\title{
Prevalence and Correlates of Cervico-Vaginal Clinical Syndromes Among Women Attending a Health Camp in Lalitpur District of Nepal
}

\author{
Johnson $\mathrm{D},{ }^{1}$ Chamot $\mathrm{E},{ }^{1}$ Lhaki $\mathrm{P},{ }^{2}$ Broker TR, ${ }^{4}$ Steben $\mathrm{M},{ }^{3}$ Shrestha $\mathrm{S}^{1}$
}

\author{
${ }^{1}$ Department of Epidemiology \\ ${ }^{2}$ Department of Biochemistry and Molecular \\ Genetics \\ University of Alabama at Birmingham \\ Birmingham, AL, USA \\ ${ }^{3}$ Nepal Fertility Care Center, Kathmandu, Nepal \\ ${ }^{4}$ Institut National de santé publique du Québec \\ Montréal (Québec) Canada
}

\section{Corresponding Author}

Sadeep Shrestha

Department of Epidemiology

University of Alabama at Birmingham

Birmingham, AL, USA

E-mail: sshresth@uab.edu

\section{Citation}

Johnson D, Chamot E, Lhaki P, Broker TR, Steben $\mathrm{M}$, Shrestha S.Prevalence and Correlates of

Cervico-Vaginal Clinical Syndromes Among Women Attending a Health Camp in Lalitpur District of Nepal. Kathmandu Univ Med J 2013;44(4):268-273.

\begin{abstract}
\section{Background}

Sexual and reproductive health of women is a major public health problem in Nepal. Screening of cervico-vaginal clinical syndromes could potentially provide insights to the prevalence of sexually transmitted infections (STIs), which is not known.
\end{abstract}

\section{Objective}

To investigate the prevalence and factors associated with cervico-vaginal clinical syndromes in the socio-behavioral, medical, and public health context of Nepal.

\section{Methods}

Married women attending a clinical health camp held by the Nepal Fertility Care Centerin Khokana of Lalitpur district were recruited to the study. Seventy-three participants completed face-to-face questionnaires on basic socio-demographic, behavioral and reproductive health factors and underwent pelvic screening including clinical diagnosis of cervicitis and vaginitis. An univariate analysis was performed to determine if any of the self-reported variables were associated with abnormal pelvic examination (cervicitis and/or vaginitis).

\section{Results}

Vaginitis was diagnosed in three (4.4\%) participants, while cervicitis was detected in 16 (23.5\%) women. None of the participants reported any high risk sexual behavior. However, $28 \%$ of the participants reported having had STI diagnosis in the past and was associated $(P<0.008)$ with abnormal pelvic results. Additionally, women with lower education were associated $(p<0.02)$ with abnormal pelvic results.

\section{Conclusions \\ The high occurrence of cervicitis in our exploratory could indicate the high prevalence of STIs. However, while there could potentially be an unknown epidemic of STIs related to the clinical syndromes, point of care testing practice might help to understand the true prevalence of STIs in Nepali women and also reduce the health burden and consequences of over treatment based on the current symptomatic diagnosis.}

\section{KEY WORDS}

Cervical Cancer, global health, HPV, Nepal, STI

\section{INTRODUCTION}

Cervico-vaginitis, a common syndrome associated with STIs in women, is associated with an increase in the risk of developing of cervical cancer. ${ }^{1}$ Risk factors associated with vaginitis and cervicitis may be early markers for sexually transmitted diseases (STIs) including human papilloma virus infection (HPV), which could subsequently be associated with cervical cancer in Nepal., ${ }^{2,3}$ The World Health Organization (WHO) states the incidence of cervical cancer in Nepal is 24.2 per 100,000, making Nepal a country with one of the highest rates of cervical cancer in the world. ${ }^{4}$ High risk (HR) HPV is known to correlate with cervical cancer. ${ }^{3}$ However, currently there is no national 
population-based data on the prevalence of STIs in Nepal.

While knowledge of STIs is high among the general population, limited studies suggest that STIs are highly prevalent among high risk groups, particularly drivers/ conductors, migrating workers, and individuals between the ages of 20 and 24. 5,6 The majority of Nepal's STIs are attributable to an active sex trade, low levels of condom use, recent political turmoil, and an increasing number of males migrating for work. ${ }^{7}$ While the high risk populations have been targeted for studies, the epidemiology of STIs in the general population has been under-studied. The aim of our pilot study was to investigate the prevalence and factors associated with the clinical syndrome of cervical and vaginal infections in the social, medical, and public health context of Nepal. Ultimately, our exploratory study will help to direct other larger studies to inform future interventions aimed at reducing STIs and related clinical outcomes in Nepal.

\section{METHODS}

Established in 1988 to complement and supplement the Nepali government's family planning programs, the Nepal Fertility Care Center (NFCC) conducts STI clinics in various regions of Nepal, covering 59 districts to date. Our study was nested within NFCC's health camp in Khokana of Lalitpur district in Kathmandu Valley. At the time of the 2011 Nepal census, Khokana had a population of 4,927 living in over 699 households. Khokana is a traditional Newari village on the outskirts of Kathmandu which is dependent on agriculture. Literacy rate of Khokana is above the national average (71.5\%). Women who attend an NFCC health camp routinely receive a wide array of free reproductive health services which include, family planning counseling, pap smear testing, vital signs, glucose, and proteinuria testing. Trained gynecologists with several years of experience in conducting pelvic examinations perform health camp pelvic exams. Volunteer nurses and health professionals who have experience conducting surveys collect demographic, social, and behavioral information from women attending the health camps. All surveyed individuals were assigned an anonymous ID to help facilitate the de-identifying of collected data. Each individual was interviewed separately from health camp attendees and was informed their individual answers would remain anonymous and confidential. The Nepal Health Research Council (NHRC) Protection of Human Subjects Committee has approved this study's protocol.

Our dependent variable was abnormal pelvic exam defined as a diagnosis of clinical syndrome of vaginitis (vaginal discharge or cervicitis (cervical discharge, and/or erosions or ulcerations of the cervix uteri) based on criteria defined by the World Health Organization. ${ }^{8}$ Covariates of interest were classified as demographic, socioeconomic, behavioral, or reproductive health variables. Demographic variables included age, weight (measured in kilograms $(\mathrm{kg})$, and ethnicity (self-reported since Kathmandu is a metropolitan area with mixed populations). Socioeconomic variables included education (illiterate, primary (1-5) school, secondary (6-12) school, or college degree and beyond), religion (open-ended), marital status (married, single, divorced, separated), age at marriage, spouse's occupation (agriculture, painting, business, housewife, labor, services, gold/silversmith, tailor or other), and annual income of the family. Behavioral variables were collected using the following questions: a) Do you have an active/regular sex life with your partner?; b) How often do you and your husband have sex (sometimes, daily, weekly or monthly, every six months, once a year)?; c) Do you currently smoke?; d) Do you currently drink alcohol?; e) How often do you drink?; f) Have you ever taken money for sex?; g) Have you ever taken food or shelter for sex?; h) Have you ever taken any illicit drugs?; i) Have you taken illicit drugs in the past 30 days? Reproductive health variables were collected using the following questionnaires: a) Do you have any children?; b) Do you use contraception?; c) Have you ever had an abortion?; d) What was your age at first marriage (if married)?; e) How many sexual partners have you had? Additional health related variables that were not classified as being demographic, socioeconomic, behavioral, or reproductive health related included a) Has anyone in your family been diagnosed with cancer? and b) What cancers were your family members diagnosed with?

Cross-tabulations were used to describe the frequencies of demographic, socioeconomic, behavioral, and reproductive health characteristics associated with an abnormal pelvic exam. Analysis of variance and Chi-square statistical tests were used to determine the association of study's continuous and categorical variables, respectively with an abnormal pelvic diagnosis.

\section{RESULTS}

Seventy three married women with a median age of 40 years (IQR: 34 - 50) participated in our study. Sixty seven women consented to have a pelvic exam, of which $19(28.4 \%)$ had an abnormal result (vaginitis and cervicitis) (Table 1). Three women (4.4\%) had signs of vaginitis while $16(23.5 \%)$ had cervicitis. Sixteen women (24\%) previously reported having had a STI. Most women had less than 10 years of education $(82 \%)$ and did not use contraception with their husbands (80\%). Most of the study participants reported "housewife" $(42.5 \%)$ as their most common occupation and "business" (52.1\%) as the most common occupation of their husband. The median annual income was 120,000 Nepali Rupees (IQR:72,000 - 220,000). Interestingly, 11/12 who reported having someone in the family with cancer had normal pelvic diagnosis. All the participants reported that at the time of survey they did not smoke or drink alcohol. At the time of the survey, a very low percentage of women reported using contraceptives (17.4\% in normal pelvic exam group and $21.1 \%$ in abnormal pelvic exam 
Table 1. Characteristics of Individuals with Normal vs. Abnormal Pelvic Exam.

\begin{tabular}{|c|c|c|c|}
\hline & $\begin{array}{l}\text { Normal } \\
\text { Pelvic Exam } \\
(\mathrm{N}=48)\end{array}$ & $\begin{array}{l}\text { Abnormal } \\
\text { Pelvic Exam } \\
(\mathrm{N}=19)\end{array}$ & P-value \\
\hline \multicolumn{3}{|l|}{ Age (years) $(n=67)$} & 0.76 \\
\hline Mean (STD) & $43.9(11.3)$ & $43.0(11.8)$ & \\
\hline Median (IQR) & $\begin{array}{c}42.5(35.0 \text { to } \\
52.0)\end{array}$ & $\begin{array}{c}39.0(34.0 \text { to } \\
50.0)\end{array}$ & \\
\hline \multicolumn{3}{|l|}{ Age (years) (n=67) } & 0.69 \\
\hline Under 30 & $3(6.3)$ & $1(5.3)$ & \\
\hline 30 to 39 & $15(31.3)$ & $9(47.4)$ & \\
\hline 40 to 49 & $15(31.3)$ & $4(21.1)$ & \\
\hline 50 and Older & $15(31.3)$ & $5(26.3)$ & \\
\hline \multicolumn{3}{|l|}{ Weight (kg) (n=65 ) } & 0.99 \\
\hline Mean (STD) & $58.8(7.7)$ & $58.8(12.1)$ & \\
\hline Median (IQR) & $\begin{array}{c}58.0(54.0 \text { to } \\
64.0)\end{array}$ & $\begin{array}{c}58.5(52.0 \text { to } \\
64.0)\end{array}$ & \\
\hline \multicolumn{3}{|l|}{ Education $(n=64)$} & 0.02 \\
\hline Illiterate & $12(26.7)$ & $6(31.6)$ & \\
\hline Primary (1-5) & $2(4.4)$ & $6(31.6)$ & \\
\hline Secondary (6-12) & $25(55.6)$ & $6(31.6)$ & \\
\hline College and Beyond & $6(13.3)$ & $1(5.3)$ & \\
\hline \multicolumn{3}{|l|}{ Religion ( $n=66$ ) } & 0.41 \\
\hline Hindu & $22(46.8)$ & $9(47.4)$ & \\
\hline Buddhist & $25(53.2)$ & $9(47.4)$ & \\
\hline Christian & $0(0)$ & $1(5.3)$ & \\
\hline \multicolumn{3}{|c|}{ Age at Marriage (years) $(n=65)$} & 0.11 \\
\hline Mean (STD) & $21.8(3.8)$ & $20.1(3.5)$ & \\
\hline Median (IQR) & $\begin{array}{c}22.0(19.0 \text { to } \\
24.0)\end{array}$ & $\begin{array}{c}19.0(18.0 \text { to } \\
23.0)\end{array}$ & \\
\hline \multicolumn{3}{|c|}{ Woman's Occupation ( $n=66)$} & 0.38 \\
\hline \multicolumn{4}{|l|}{ Agriculture } \\
\hline \multicolumn{4}{|l|}{ Painting } \\
\hline \multicolumn{4}{|l|}{ Business } \\
\hline \multicolumn{4}{|l|}{ Housewife } \\
\hline \multicolumn{4}{|l|}{ Labor } \\
\hline \multicolumn{4}{|l|}{ Service } \\
\hline \multicolumn{4}{|l|}{ Gold/Silver } \\
\hline \multicolumn{4}{|l|}{ Tailor } \\
\hline \multicolumn{3}{|c|}{ Husband's Occupation ( $n=65)$} & 0.22 \\
\hline Painting & $5(10.6)$ & $0(0)$ & \\
\hline Business & $22(46.8)$ & $11(61.1)$ & \\
\hline Labor & $11(23.4)$ & $3(16.7)$ & \\
\hline Service & $6(12.8)$ & $2(11.1)$ & \\
\hline Gold/Silver & $1(2.1)$ & $1(5.6)$ & \\
\hline Unemployment & $2(4.3)$ & $1(5.6)$ & \\
\hline \multicolumn{3}{|c|}{ Annual Income(Nepali Rupees) $(n=67)$} & 0.38 \\
\hline Mean (STD) & $\begin{array}{c}203,142 \\
(252,478.0) \\
135,000\end{array}$ & $\begin{array}{c}164333.3 \\
(110,650.4) \\
135,000\end{array}$ & \\
\hline Median (IQR) & $\begin{array}{c}(5,000 \text { to } \\
200,000)\end{array}$ & $\begin{array}{c}(100,000 \text { to } \\
220,000)\end{array}$ & \\
\hline
\end{tabular}

\begin{tabular}{|c|c|c|c|}
\hline & $\begin{array}{c}\text { Normal } \\
\text { Pelvic Exam } \\
(\mathrm{N}=48)\end{array}$ & $\begin{array}{l}\text { Abnormal } \\
\text { Pelvic Exam } \\
(\mathrm{N}=19)\end{array}$ & P-value \\
\hline \multicolumn{3}{|c|}{ Do you have any Children $(n=66)$} & 0.37 \\
\hline Yes & $43(91.5)$ & $18(94.7)$ & \\
\hline No & $4(8.5)$ & $1(5.3)$ & \\
\hline \multicolumn{3}{|c|}{ Do you use Contraception ( $n=65$ ) } & 0.73 \\
\hline Yes & $8(17.4)$ & $4(21.1)$ & \\
\hline No & $38(82.6)$ & 15 (78.9) & \\
\hline \multicolumn{3}{|c|}{ Have you ever had an Abortion $(n=64)$} & 0.76 \\
\hline Yes & $14(29.8)$ & $6(35.3)$ & \\
\hline No & $33(70.2)$ & $11(64.7)$ & \\
\hline
\end{tabular}

Do you have a Active/Regular Sex Life with your Partner $(n=67)$

$\begin{array}{lll}\text { Yes } & 37(77.1) & 13(68.4) \\ \text { No } & 11(22.9) & 6(31.6)\end{array}$

How Often do you and your Husband have Sex $(n=52)$

\begin{tabular}{|c|c|c|}
\hline Daily & $2(5.6)$ & $0(0)$ \\
\hline Weekly & $22(61.1)$ & $8(61.5)$ \\
\hline Monthly & $10(27.8)$ & $5(38.5)$ \\
\hline Every 6 months & $2(5.6)$ & $0(0)$ \\
\hline \multicolumn{3}{|c|}{ Age at First Sex $(n=67)$} \\
\hline Mean (STD) & $21.5(3.5)$ & $20.9(4.2)$ \\
\hline Median (IQR) & $\begin{array}{c}20.5 \text { (19.0 to } \\
24.0)\end{array}$ & $\begin{array}{c}20.0(18.0 \\
24.0)\end{array}$ \\
\hline \multicolumn{3}{|c|}{ Have you ever been diagnosed with and STI $(n=66$} \\
\hline Yes & 7 (14.9) & $9(47.4)$ \\
\hline No & $40(85.1)$ & $10(52.6)$ \\
\hline
\end{tabular}

Has anyone in your family had cancer $(n=66)$

0.16

$\begin{array}{lcc}\text { Yes } & 11(23.4) & 1(5.3) \\ \text { No } & 36(76.6) & 18(94.7) \\ \text { Which cancers }(\mathbf{n = 1 2 )} & & \\ \text { Lung } & 2(18.2) & 0(0) \\ \text { Stomach } & 3(27.3) & 0(0) \\ \text { Blood } & 2(18.2) & 0(0) \\ \text { Liver } & 2(18.2) & 0(0) \\ \text { Cervix } & 1(9.1) & 1(100.0) \\ \text { Intestinal } & 1(9.1) & 0(0)\end{array}$

Do you Currently Smoke $(n=66)$

n/a

\begin{tabular}{|c|c|c|c|}
\hline Yes & $0(0)$ & $0(0)$ & \\
\hline No & $47(100.0)$ & $19(100.0)$ & \\
\hline \multicolumn{3}{|c|}{ Do you Currently Drink Alcohol $(n=67)$} & 0.42 \\
\hline Yes & $24(50.0$ & $12(63.2)$ & \\
\hline No & $24(50.0$ & $7(36.8)$ & \\
\hline \multicolumn{3}{|c|}{ How often do you drink $(n=40)$} & 0.78 \\
\hline Sometimes & $15(55.6)$ & $8(61.5)$ & \\
\hline Daily & $0(0)$ & $1(7.7)$ & \\
\hline Weekly & $2(7.4)$ & $1(7.7)$ & \\
\hline Monthly & $5(18.5)$ & $2(15.4)$ & \\
\hline Every 6 Months & $3(11.1)$ & $0(0)$ & \\
\hline Once a year & $2(7.4)$ & $1(7.7)$ & \\
\hline
\end{tabular}


group) and $29.8 \%$ (normal) and 35.3\% (abnormal) reported ever having an abortion in the two groups (Table 1 ).

Several variables were uniformly answered as either yes or no by $100 \%$ of study participants and thus analyses could not be performed (Table 1). All women reported being married, heterosexual, never smoking or using other tobacco products, never taking money for sex, and having never taken food or shelter for sex.All but one woman reported to be from the local ethnic group, "Newar". All women reported their husbands as the only sexual partner during their lifetime. Univariate analysis indicated that education $(p<0.02)$ and having been previously diagnosed with an STI $(p<0.008)$ were significantly associated with an abnormal pelvic exam.

\section{DISCUSSION}

Twenty eight percent of our study population had a clinical syndrome of cervico-vaginal infection, classified according to WHO algorithms as either vaginitis $(4.4 \%)$ or cervicitis (23.5\%). Cervico-vaginal infections have several etiological factors that make it difficult to obtain a single reference percentage. It is estimated that more than $90 \%$ of vaginitis is caused by either bacterial vaginosis (40-50\%), candidiasis (20-25\%), ortrichomoniasis (15-20\%), while, cervicitis is mostly caused by infections with chlamydia, gonorrhea, herpes simplex virus, and trichomoniasis. ${ }^{9-11}$

Little is known about the rates of cervico-vaginal infections in the general population("low-risk") in Nepal. However, in developed countries like the U.S, approximately five to ten million office visits per year are attributed to vaginitis and cervicitis. ${ }^{12}$ The prevalence of trichomosiasis and gonorrheain the U.S. is $8 \%$ and $2.4 \%$, and the prevalence of the herpes simplex virus is approximately $16 \% .^{13,14}$ In Nepal's neighboring country, India, a survey of 3659 individuals from the cities of Bangalore, Hyderabad and Chandigarh indicated that $10.1 \%$ of population was positive for HSV-2 while the prevalence of syphilis in the surveyed population was $1.7 \% .{ }^{15}$ If left untreated, STIs can potentially lead to serious long-term reproductive health consequences, such as miscarriage, premature birth, pelvic inflammatory disease, and sterility. ${ }^{16-18}$

Data in this exploratory study suggests a high rate of syndromic cervicitis in the Nepali women who attended the health camp. Given cervicitisis often caused by STIs, current symptomatic diagnosis of cervico-vaginal warrants further etiological testing since many STI are asymptomatic and would not be covered by the syndromic approach. "Point of care" testing (POCT) for the presence of STIs is able to deliver a more accurate, rapid and cost-effective form of STI testing by bringing medical testing equipment near or at the site of patient care and would be an excellent alternative, specifically for management of asymptomatic STIs in the Nepali women. ${ }^{19}$

Syndromic management may have some benefits but over treatment may be a concern. On the contrary, it has been reported that in some settings, symptomatic management can result in as high as $98 \%$ over treatment for Chlamydia and gonorrhea in women presenting with vaginal discharge..$^{20}$ Our measured outcome of a diagnosis of clinical syndrome of cervico-vaginal infection is based on the diagnosis of clinical symptoms which prevents us from knowing the sensitivity and specificity of each diagnosis. Thus, asymptomatic STI infection and over treatment needs to be balanced to reduce the burden of STIs in the general population in Nepal.

With a reported sensitivity ranging between $29-70 \%$ and specificity ranging between 30-85\%,symptomatic STI diagnosis has been suggested to be an inadequate method of STI testing that is only partially able to control STIs on a population level. ${ }^{21,22}$ Utilizing simple and cost-effective POCT for the detection of STIs would help to dramatically increase the quality of reproductive health care of Nepali women who do not have consistent access to medical services. Benefits to POCT included rapid decision making by medical staff, patient test results on the same visit, and increased STI control on a population level. ${ }^{23}$ In a resource poor setting such as Nepal, POCT would also produce an opportunity to improve post-test counseling, which would in turn increase reproductive health knowledge on a community level. The World Health Organization (WHO) launched a STI Diagnostics Initiative (SDI) in 1990 and currently has prioritized to improve STI evaluation with the following criteria, ASSURED: Affordable, Sensitive, Specific, User-friendly, Rapid and Robust, Equipment-free, Delivered; which also emphasizes the utilization of POCT. ${ }^{24}$

It is possible that gender disparities in education and Nepal's poor capacity to teach reproductive health are motivating factors behind our study's high rates of cervicitis. The Nepali government provides a package of sexual and reproductive health education through school based services under the National Adolescent Health and Development Strategy and the Young People Development Program. However, despite school-based programs on sexual health, the teaching of sexual health is often very poor or not fully evaluated. ${ }^{6,25}$ Teachers are often too embarrassed to talk about sex and usually do not have the proper training to address the needs of students. ${ }^{26}$ There are also a large proportion of women who leave school before they receive a secondary education, thereby missing a significant portion of the government's reproductive health programs. ${ }^{27,28}$

All women interviewed for this study indicated that they did not take money, food or shelter for sex, did not use illegal drugs, and were not current smokers. All women also reported their husbands as the only sexual partner during their lifetime. However, despite reporting any high risk behaviors, $24 \%$ of women reported previously having an STI and $28 \%$ of women were diagnosed with a clinical syndrome of cervico-vaginal infection at our health camp. These findings suggest a strong sense of social stigma surrounding issues of sexual health, including the 
activities of husbands or male partners. We attempted to mitigate the social stigma of reporting risk factors by having female researchers administer the interviews and assured participants that individual answers given would remain confidential. Despite this, study participants were reluctant to report high risk behavior. Perhaps more rigorous qualitative research approaches might help uncover the relations among risk of abnormal pelvic exam, social norms and individual attitudes and practices.

Based on the self-reported ethnicity of the health camp participants, our study was conducted in a relatively homogenous population in the Lalitpur district of Kathmandu, making it difficult to generalize our findings to other areas of Kathmandu or Nepal. Like several South Asian countries, the ethnic landscape of Nepal varies widely across different cultures and ethnic groups. Many of these different ethnic groups have their own social norms and values about sexuality making it impossible to generalize our results to the whole of Nepal. Social stigma and discomfort talking about sexual matters could potentially mask an epidemic of STIs even among women visiting clinics, such as those in our study. This will be more important in other high-risk groups such as commercial sex workers and migrant workers and women with multiple sex partners. Our study's small sample size and potential selection bias of participants at a health camp are possible limitations to our study. However, with a sample size of 73 women we were unable to reliably investigate risk factors of cervico-vaginal clinical syndromes while adjusting for cofounders. By providing free clinical services directly to the Khokana community it is possible women with cervicovaginal clinical syndromes would be inclined to participate in our health camp in greater proportions than healthy women. Nevertheless, we have assessed factors related to those syndromes, which may or may not be generalizable to women in Nepal or Khokana.

\section{CONCLUSION}

This exploratory study might provide some insights to a potential problem of STIs that warrants large-scale studies of screening and prevention where available (e.g. HPV vaccine) in different regions and ethnic groups for a comprehensive evaluation of women's reproductive health in Nepal. This will require collaborative investment and commitment at all levels of academic, health care service, local government, national and international organizations and specifically the local community.

\section{ACKNOWLEDGEMENT}

We thank the study participants and the staff at Nepal Fertility Care Center (NFCC) who helped with the data collection. The study was in part supported by the pilot fund from the department of epidemiology, UAB School of Public Health (EC and SS). DJ was supported by a National Institutes of Health Cancer Prevention and Control Training Grant (R25CA47888).

\section{REFERENCES}

1. Gram IT, Macaluso M, Churchill J, Stalsberg H. Trichomonas vaginalis (TV) and human papillomavirus (HPV) infection and the incidence of cervical intraepithelial neoplasia (CIN) grade III. Cancer Causes Control. 1992 May;3(3):231-6.

2. Ghosh I, Ghosh P, Bharti AC, Mandal R, Biswas J, Basu P. Prevalence of human papillomavirus and co-existent sexually transmitted infections among female sex workers, men having sex with men and injectable drug abusers from eastern India. Asian Pac J Cancer Prev. 13(3):799802.

3. Maucort-Boulch D, Franceschi S, Plummer M. International correlation between human papillomavirus prevalence and cervical cancer incidence. Cancer Epidemiol Biomarkers Prev. 2008 Mar;17(3):71720.

4. WHO/ICO. Information Centre on HPV and Cervical Cancer (HPV Information Centre). Human Papillomavirus and Related Cancers in Nepal. Summary Report 2010.

5. (MOHP) MoHaP. Nepal Demographic and Health Survey 2006. Kathmandu: Ministry of Health and Population 2007.

6. Regmi P, Simkhada P, Van Teijlingen ER. Sexual and reproductive health status among young peoples in Nepal: opportunities and barriers for sexual health education and services utilization. Kathmandu Univ Med J (KUMJ). 2008 Apr-Jun;6(2):248-56.

7. Simkhada B, van Teijlingen ER, Porter M, Simkhada P. Major problems and key issues in Maternal Health in Nepal. Kathmandu Univ Med J (KUMJ). 2006 Apr-Jun;4(2):258-63.

8. Organization WH. Training modules for the syndromic management of sexually transmitted infections. Geneva World Health Organization 2007.

9. Wilson JF. In the clinic. Vaginitis and cervicitis. Annals of internal medicine. 2009 Sep 1;151(5):3-6.

10. Hainer BL, Gibson MV. Vaginitis. Am Fam Physician. 2011 Apr 1;83(7):807-15.

11. Lusk MJ, Konecny P. Cervicitis: a review. Curr Opin Infect Dis. 2008 Feb;21(1):49-55.

12. Paavonen J, Stamm WE. Sexually transmitted diseases. Lower genital tract infections in women. Infect Dis Clin North Am. 1987 Mar;1(1):179-98.

13. Workowski KA, Berman S. Sexually transmitted diseases treatment guidelines, 2010. MMWR Recomm Rep. Dec 17;59(12):1-110.

14. CDC. Genital Herpes - CDC Fact Sheet. Atlanta2013: Available from: http://www.cdc.gov/std/herpes/STDFact-Herpes.htm.

15. Sgaier SK, Mony P, Jayakumar S, McLaughlin C, Arora P, Kumar R, et al. Prevalence and correlates of Herpes Simplex Virus-2 and syphilis infections in the general population in India. Sex Transm Infect. Mar;87(2):94-100.

16. Paavonen J, Eggert-Kruse W. Chlamydia trachomatis: impact on human reproduction. Hum Reprod Update. 1999 Sep-Oct;5(5):433-47.

17. Bebear C, de Barbeyrac B. Genital Chlamydia trachomatis infections. Clin Microbiol Infect. 2009 Jan;15(1):4-10.

18. Gomez GB, Kamb ML, Newman LM, Mark J, Broutet N, Hawkes SJ. Untreated maternal syphilis and adverse outcomes of pregnancy: a systematic review and meta-analysis. Bull World Health Organ. Mar 1;91(3):217-26.

19. Kost GJ. Goals, guidelines and principles for point-of-care testing. Hagerstwon: Lippincott Williams \& Wilkins; 2002. 
20. Peeling RW. Utilisation of Rapid Tests for Sexually Transmitted Infections: Promises and Challenges. The Open Infectious Diseases Journal. 2009;3:156-63.

21. CDC. Sexually transmitted disease surveillance, 2010. Atlanta 2011 [cited 2013 June 02]; Available from: http://www.cdc.gov/std/ stats10/surv2010.pdf.

22. Kapiga SH, Vuylsteke B, Lyamuya EF, Dallabetta G, Laga M. Evaluation of sexually transmitted diseases diagnostic algorithms among family planning clients in Dar es Salaam, Tanzania. Sex Transm Infect. 1998 Jun;74 Suppl 1:S132-8.

23. Gift TL, Pate MS, Hook EW, 3rd, Kassler WJ. The rapid test paradox: when fewer cases detected lead to more cases treated: a decision analysis of tests for Chlamydia trachomatis. Sex Transm Dis. 1999 Apr;26(4):232-40.
24. Peeling RW, Holmes KK, Mabey D, Ronald A. Rapid tests for sexually transmitted infections (STIs): the way forward. Sex Transm Infect. 2006 Dec;82 Suppl 5:v1-6.

25. Pradhan A SM. Adolescent and youth reproductive health in Nepal: status, issues, policies, and programmes; Policy Project. Kathmandu 2003.

26. Pokharel S, Kulczycki A, Shakya S. School-based sex education in Western Nepal: uncomfortable for both teachers and students. Reprod Health Matters. 2006 Nov;14(28):156-61.

27. Bajracharya A, Amin S. Poverty, marriage timing, and transitions to adulthood in Nepal. Stud Fam Plann. Jun;43(2):79-92.

28. Vogel A, Korinek K. Passing by the girls? Remittance allocation for educational expenditures and social inequality in Nepal's households 2003-2004. Int Migr Rev.46(1):61-100. 